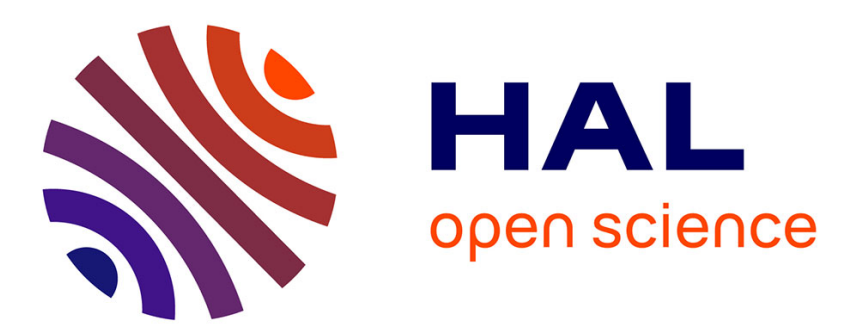

\title{
Identifying new Risk Markers and Potential Targets: The Value of the Proteome
}

\author{
Anatol Kontush
}

\section{To cite this version:}

Anatol Kontush. Identifying new Risk Markers and Potential Targets: The Value of the Proteome. Cardiovascular Drugs and Therapy, 2016, 30 (1), pp.13-18. 10.1007/s10557-016-6656-3 . hal-01304892

\section{HAL Id: hal-01304892 https://hal.sorbonne-universite.fr/hal-01304892}

Submitted on 20 Apr 2016

HAL is a multi-disciplinary open access archive for the deposit and dissemination of scientific research documents, whether they are published or not. The documents may come from teaching and research institutions in France or abroad, or from public or private research centers.
L'archive ouverte pluridisciplinaire HAL, est destinée au dépôt et à la diffusion de documents scientifiques de niveau recherche, publiés ou non, émanant des établissements d'enseignement et de recherche français ou étrangers, des laboratoires publics ou privés. 
Identifying new risk markers and potential targets: The value of the proteome

Anatol Kontush

National Institute for Health and Medical Research (INSERM), Research Unit 1166 ICAN;

University of Pierre and Marie Curie - Paris 6; Pitié - Salpétrière University Hospital; Paris,

France

Keywords: proteomics; biomarkers; cardiovascular disease

${ }^{*}$ Corresponding author: Dr. Anatol Kontush, INSERM UMRS 1166, 91, boulevard de l'Hôpital, 75013 Paris, France. Tel. 33-1-4217 7976. Fax 33-1-4582 8198. E-mail anatol.kontush@upmc.fr 
Abstract. Several protein biomarkers, including cardiac troponin T, cardiac troponin I, Btype natriuretic peptide, C-reactive protein and apolipoprotein A-I, are widely employed in the evaluation of cardiovascular disease. Several of such potential biomarkers, or their multiscores, have been assessed over the last years for the prediction of cardiovascular risk but only a few of them have been validated for clinical use. Substantial improvement in the cardiovascular risk prediction and reclassification relative to traditional models therefore remains a difficult task presently unresolved. Hence, a potential importance of alternative approaches which may rely on novel proteomic biomarkers among others. Plasma or serum concentrations of numerous proteins were measured using proteomic approaches to establish their relationships with cardiovascular disease; none of them was however evaluated for cardiovascular risk prediction and subject stratification in rigorous large-scale studies. Thus, further research is needed to identify novel candidates that can improve cardiovascular risk prediction, subject stratification and standard care. Proteomics will undoubtedly remain a key approach to address this major clinical and scientific challenge. 


\section{Introduction}

The concept of proteomics aims at characterizing and quantifying the proteome - all proteins present in a biological fluid, biological tissue or a given cell type. The term "proteome” was coined by Mark Wilkins as early as 1994 to describe total protein composition of a biological tissue or cell type [1]. Key technical advancements, including developments of soft ionisation techniques and specialized algorithms to analyse the proteome, occurred over this time to allow quantitative assessment of the proteome. As a result, proteomics has emerged as a tool to evaluate metabolic alterations present in a disease state or pathological condition. Multiple applications of proteomic analyses to the clinics have been developed to contribute to our understanding of molecular mechanisms of diseases and to identify potential biomarkers of disease presence and progression.

Biomarkers are molecules whose levels provide information about disease. Biomarkers are typically determined in biological fluids that can be readily obtained under clinical conditions, primarily in plasma, serum and urine. Measurements of biomarkers can be valuable to diagnose the disease, to assess its progression, to monitor effects of a therapy, to discover novel therapeutic targets and to understand molecular mechanisms underlying the disease development. The importance of the biomarker development in the field of cardiovascular (CV) disease, which represents the leading cause of death in industrialized countries, is highlighted by the need of improved strategies for the primary prevention of CV disease. Indeed, predictive value of current risk-assessment models remains limited, with a large proportion of patients without traditional risk factors (up to 20\%) [2, 3]. Thus, novel diagnostic and prognostic biomarkers of CV risk bear a potential to improve the selection of individuals for preventative strategies and to ameliorate disease management. This review 
summarizes our current knowledge of the value of proteomics to discover new biomarkers and targets in the field of CV disease.

\section{Novel protein biomarkers and CV risk prediction}

Several protein biomarkers are widely employed in the evaluation of CV disease (Table 1). Thus, cardiac troponin $\mathbf{T}$ and cardiac troponin I (cTnI) are used for the diagnosis of acute coronary syndromes and myocardial infarction (MI), B-type natriuretic peptide (BNP) and its $\mathrm{N}$-terminal form are employed to diagnose congestive heart failure, C-reactive protein (CRP) is a useful biomarker of inflammation in atherosclerosis, and apolipoprotein A-I (apo

A-I) is an excellent risk predictor of CV risk related to the metabolism of high-density lipoprotein (HDL).

Troponin T represents the classical biomarker of MI possessing a high predictive value for the disease [4]; elevated plasma levels of this molecule constitute the gold standard approach to detect MI [5]. Circulating concentrations of BNP reveal strong associations with CV risk under a range of different clinical conditions [6]. Similarly, circulating levels of CRP are strongly associated with CV disease [7]. Finally, plasma levels of apoA-I, the major protein components of HDL, can be superior to HDL-cholesterol as a predictor of CV risk [8]. However, the guidelines of the American College of Cardiology Foundation and the American Heart Association (ACCF/AHA) released in 2010 largely failed to add proteinderived measurements to the list of clinically useful biomarkers of CV disease [9]. Indeed, only the evaluation of family history of CV disease received a class I recommendation, the highest possible level of a clinical importance. Remarkably, circulating levels of CRP and BNP firmly established to be strongly associated with CV disease were concluded to only 
modestly improve CV risk assessment when evaluated together with traditional CV risk factors $[10,6,11]$. In a more recent report, levels of high-sensitivity troponin T (hsTnT) were associated with CV mortality but only marginally imporved a traditional risk factor model in the Dallas Heart Study [12]. In a similar fashion, plasma levels of apoA-I are not always superior to HDL-cholesterol as a predictor of CV risk [13]. Finally, growth-differentiation factor- 15 (GDF-15) expressed by cardiomyocytes under conditions of ischaemia or pressure-related stress was a strong predictor of all-cause, CV and non-CV mortality but only moderately improved prediction of all-cause mortality in the Rancho Bernardo Study [14]. Such negative results may in part reflect the lack of causative relationships of a given biomarker with the disease. Thus, Mendelian randomization studies evaluating subjects with genetically determined CRP levels do not support a causative role of the protein in the development of $\mathrm{CV}$, suggesting that CRP is a biomarker rather than a cause of atherosclerosis [15].

In order to improve risk predicition using individual protein biomarkers, they were proposed to be combined into a multi-biomarker score (“multiscore”). Such approach is based on the assumption that biomarkers to be combined reflect different pathophysiological pathways independently contributing to CV disease, which is not always valid. Thus, in the Framingham Offspring Study, five biomarkers, and notably BNP, CRP, urinary albumin/creatinine ratio, homocysteine and renin, out of ten selected on the basis of known associations with CV risk, were retained as predictors of death [16]. In addition, two biomarkers (BNP and urinary albumin/creatinine ratio) were retained as predictors of CV events. A multiscore constructed using the ten biomarkers was significantly related to allcause mortality and CV events; however, assessment of CV risk was only minimally improved relative to the model containing traditional CV risk factors. Similarly, two of six biomarkers, and notably BNP and mid-region pro-adrenomedullin, were retained as predictors 
of CV events in the Swedish Malmo Diet and Cancer cohort [10]. A multiscore constructed using the biomarkers was significantly related to the risk of coronary events but the risk prediction was only marginally improved when the multiscore was added to traditional risk factors. Finally, four biomarkers (troponin I, N-terminal of the prohormone BNP (NTproBNP), CRP and cystatin C) only modestly improved prediction of CV and all-cause mortality in elderly men without CV disease in the Uppsala Longitudinal Study of Adult Men when added to a traditional risk factor model [17]. An attempt to add a larger number of novel biomarkers to the traditional risk prediction model was similarly unsuccessful as revealed by the Women's Health Initiative cohort in which five (out of 18) biomarkers moderately improved CV risk prediction [18]. Simialr results were observed in the MORGAM study that evaluated 30 biomarkers, including NT-proBNP, CRP and troponin I, none of which alone was capable of improving discrimination in terms of CV risk [19]. A combination of NTproBNP, CRP and troponin I only slightly improved the discrimination.

\section{Potential novel proteomic biomarkers of CV disease}

The data on the evaluation of CV risk with a help of circulating levels of individual proteins, or using a multiscore built of their combinations, reveal that substantial improvement in the risk prediction and reclassification relative to traditional models remains a difficult task presently unresolved. Hence, a potential importance of alternative approaches which may rely on novel proteomic biomarkers among others.

Plasma or serum concentrations of numerous proteins were measured using proteomic approaches to evaluate their relationships with CV disease (Table 1 and Figure 1); none of them was however evaluated for CV risk prediction and subject stratification in rigorous large-scale studies. Elevated plasma levels of several proteins were documented in MI (Figure 
1). Thus, concentrations of creatine kinase CK-MB were increased in plasma following MI [20, 21], while concentrations of fatty acid-binding protein (FABP) were elevated in MI, stroke and coronary artery disease (CAD) [22, 21, 23]. Positive associations with MI were also observed for plasma levels of cyclophilin A, cluster of differentiation 5 molecule [CD5] antigen-like, mucin cell surface associated protein 18 [MUC-18], a cell-surface glycoprotein, collagen $\alpha-1$ (XVIII) chain, salivary $\alpha$-amylase 1, CRP and multimerin-2 [24]. In another study, plasma concentrations of apoC-I, apoC-II and apoE were found to be elevated in ST segment elevated MI as revealed by multiple reaction monitoring (MRM) proteomic measurements [25]. In a simalr fashion, levels of myeloperoxidase (MPO) were capable of predicting CV events in patients with CAD [26]. In addition, cardiac myosinbinding protein C (cMyBP-C) was strongly increased in patients with non-ST segment elevated MI [27].

By contrast, onset of MI was associated with diminished concentrations of retinol-binding protein 4 (RBP4) $[28,29]$. Another plasma protein whose levels can be negatively related to CV disease is exemplified by heat shock protein-27 (HSP27) that appears to be reduced in myocardial ischemia [30, 31]. Indeed, HSP27 concentrations are decreased in the blood of patients with carotid stenosis relative to healthy subjects [30]. In addition, low circulating levels of HSP27 are associated with the presence of CAD and prognostic of future adverse clinical events [31]. In a prospective study of initially healthy women, baseline HSP27 concentrations in plasma were however not associated with incident CV events [32]. Plasma levels of soluble tumor necrosis factor-like weak inducer of apoptosis (sTWEAK) are equally decreased in patients with CAD [33], abdominal aortic aneurysm [34] and chronic heart failure [35]. Furthermore, sTWEAK concentrations were capable of predicting CV disease in renal transplant patients [36]. 
When proteomic analysis was applied to pooled plasma samples obtained from CAD patients and controls in order to identify low-abundance proteins, 95 differential protein signals were identified, including those of CA11, CD59, CHFR-1, collagen $\alpha$-3(VI) chain, complement

\section{C1s, defensin 5, emilin 3/multimerin-2, fibrinogen $\gamma$ chain, GST-omega-1, IGF binding} complex acid labile chain, secreted phosphoprotein 24 and some other proteins involved in natural defenses, inflammation, growth and coagulation [23].

While a vast majority of the proteomic studies were performed in plasma or serum, urine was occasionally employed (Table 1). Thus, urine levels of collagen $\alpha-1(I)$ and collagen $\boldsymbol{\alpha}-\mathbf{1 ( I I I )}$ were augmented in CAD patients relative to controls [37]. In some studies, proteins were measured in isolated lipoproteins rather than in whole plasma; the presence of apoC-III in HDL [38] and LDL [39] was thereby identified as a factor associated with CV disease. In addition, other proteins, including serum amyloid A and complement C3, were reported to be elevated in HDL from CAD patients relative to controls [40, 41].

Proteomic approaches have equally been applied to discover new biomarkers of cardiomyopathy and heart failure to improve risk assessment in these conditions (Table 1), which is presently based on the measurement of BNP firmly established as a gold-standard biomarker for this pathological condition. Thus, myosin heavy chain 7 (MYH7), desmin, insulin-like growth factor-binding protein 7 (IGFBP7) and annexin A2 were initially proposed to represent circulating biomarkers of cardiomyopathy-induced heaft failure in a transgenic mouse model to be subsequently validated in humans [42]. In another study, quiescin Q6 (QSOX1) was reported to represent a biomarker for acute heart failure [43]. A strength of proteomic analyses involves their capacity to quantitatively assay proteins displaying post-translational modifications, which are typically present in the circulation at low abundance and whose levels can be altered by CV disease. Major post-translational protein modifications include phosphorylation, glycation and oxidation. Altered 
phosphorylation of numerous proteins is observed in CV diseases; phosphorylation of cardiac Troponin I was documented as a potential biomarker of chronic heart failure [44]. Advanced glycation end products (AGEs) can accumulate on several proteins in patients with CV disorder [45]. In addition, key plasma proteins, including apoA-I, $\alpha$-1-antitrypsin and fibrinogen, can also become oxidized, reflecting elevated oxidative stress in CV disease [46, 47]. It remains however unclear as to whether post-translational protein modifications can serve as biomarkers of the disease.

\section{Technical challenges}

Despite generating wide-spread enthusiasm and providing first promising data, proteomic methods face considerable technical challenges [48, 49]. Thus, proteomic quantification of circulating protein concentrations is complicated by their wide dynamic range. This question can be addressed by protein fractionation and depletion before LC/MS analysis. High interindividual variability represents another issue, which can be resolved by enlarging study cohorts. Proteomics of post-translational modifications requires high-resolution and highsensitivity mass-spectrometrical methodology.

Next, there still remains a gap between candidate biomarkers and their clinical applications. Numerous candidate proteins discovered in original proteomic studies often do not survive rigorous validation in follow-up investigations, implying a risk of false-positive reports and calling for stringent verification approaches.

In addition, biological importance of proteomic data obtained is frequently difficult to deduce from extensive numerical information reported, complicating data interpretation. Quantitative alterations discovered by proteomics need to be linked to biological function and integrated 
with other "omics” data; modern computational and visualization tools, including network models and protein interaction networks, can provide a major progress in this regard. Finally, “classical” issues of LC/MS/MS analyses need to be addressed to ameliorate resolution, sensitivity, specificity, throughput, precision and accuracy of the assays, to standardize procedures for sample collection, preparation and analysis, and to lower the assay costs.

\section{Conclusions and perspectives}

Proteomic studies have revealed that plasma concentrations of numerous proteins are associated with CV disease. Several of such potential biomarkers for the prediction of CV risk have been evaluated over the last years but only a few of them have been validated for clinical use. Such predominantly negative findings highlight inherent difficulties of the biomarker discovery and validation, calling for further research to identify novel candidates that can improve CV risk prediction, subject stratification and standard care. Assuming major technical issues successfully resolved, new and powerful high-throughput proteomic platforms can ensure translation of technical advancements into clinical practice to further reduce the burden of CV disease [50].

In addition to clinical biomarkers, proteomic strategies can provide a valuable tool to identify proteins involved in CV disease, which may become therapeutic targets. Computational approaches which combine protein identity with biological pathways and activities are critical to uncover the role of proteins as functional mediators of disease [51]. Alternative sources of biological material, such as atherosclerotic plaques, circulating cells and plasma extracellular vesicles, can deliver novel information on physiopathological mechanisms underlying associations discovered by proteomics of biological fluids [52]. These considerations leave 
little doubt that proteomics will both open wide diagnostic perspectives and drive basic science research in the field of CV disease in the near future. 


\section{Acknowledgements}

These studies were supported by National Institute for Health and Medical Research (INSERM), Paris, France. 


\section{Figure Legend}

Figure 1. Alterations in circulating concentrations of proteomic biomarkers in patients with CV disease relative to controls. Biomarkers with reduced concentrations are shown on the left, while those with elevated concentrations are listed on the right. For references see Table 1. 
Table 1. Circulating proteomic biomarkers of CV disease

\begin{tabular}{lll}
\hline Protein & Disease & Ref. \\
\hline Annexin A2 & HF & {$[42]$} \\
ApoA-I & CAD & {$[8]$} \\
ApoC-I & MI & {$[25]$} \\
ApoC-II & MI & {$[25]$} \\
ApoE & MI & {$[25]$} \\
BNP & CAD, MI, HF & {$[10,6,11]$} \\
CA11 & CAD & {$[23]$} \\
Cardiac Tn I & MI & {$[4,5]$} \\
CD59 & CAD & {$[23]$} \\
CD5L & MI & {$[24]$} \\
CHFR-1 & CAD & {$[23]$} \\
CK-MB & MI & {$[20,21]$}
\end{tabular}




$\begin{array}{lll}\text { cMyBP-C } & \text { MI } & {[27]} \\ \text { Collagen } \alpha \text {-3(VI) chain } & \text { CAD } & {[23]} \\ \text { Collagen } \alpha \text {-1(I) chain* } & \text { CAD } & {[37]} \\ \text { Collagen } \alpha \text {-1(III) chain* } & \text { CAD } & {[37]} \\ \text { Collagen } \alpha \text {-1(XVIII) chain } & \text { MI } & {[24]} \\ \text { Complement C1s } & \text { CAD } & {[23]} \\ \text { CRP } & \text { MI } & {[10,6,11,7,24]} \\ \text { Cyclophilin A } & \text { MI } & {[24]} \\ \text { Defensin 5 } & \text { CAD } & {[23]} \\ \text { Desmin } & \text { HF } & {[42]} \\ \text { Emilin 3/Multimerin-2 } & \text { CAD } & {[23,24]} \\ \text { FABP } & \text { MI } & {[22,21,23]} \\ \text { Fibrinogen } \gamma \text { chain } & \text { CAD } & {[23]} \\ \text { GDF-15 } & \text { CAD } & {[14]} \\ \text { GST-omega-1 } & \text { CAD } & {[23]} \\ \text { HSP27 } & & {[30,31]}\end{array}$




\begin{tabular}{lll} 
IGF binding complex acid labile chain & CAD & {$[23]$} \\
IGFBP7 & HF & {$[42]$} \\
MPO & CAD & {$[26]$} \\
MUC-18 & MI & {$[24]$} \\
Multimerin-2 & MI & {$[24]$} \\
MYH7 & HF & {$[42]$} \\
QSOX1 & HF & {$[43]$} \\
RBP4 & MI & {$[28,29]$} \\
Salivary $\alpha$-amylase-1 & MI & {$[24]$} \\
Secreted phosphoprotein 24 & CAD & {$[23]$} \\
sTWEAK & CAD, HF & {$[33,35]$} \\
\hline
\end{tabular}

* Determined in urine; all other proteins measured in plasma or serum. HF, heart failure. 


\section{References}

1. Wilkins MR, Sanchez JC, Gooley AA, Appel RD, Humphery-Smith I, Hochstrasser DF et al. Progress with proteome projects: why all proteins expressed by a genome should be identified and how to do it. Biotechnol Genet Eng Rev. 1996;13:19-50.

2. Khot UN, Khot MB, Bajzer CT, Sapp SK, Ohman EM, Brener SJ et al. Prevalence of conventional risk factors in patients with coronary heart disease. JAMA. 2003;290(7):898-904. doi:10.1001/jama.290.7.898.

3. Hozawa A, Folsom AR, Sharrett AR, Chambless LE. Absolute and attributable risks of cardiovascular disease incidence in relation to optimal and borderline risk factors: comparison of African American with white subjects--Atherosclerosis Risk in Communities Study. Arch Intern Med. 2007;167(6):573-9. doi:10.1001/archinte.167.6.573.

4. Tiwari RP, Jain A, Khan Z, Kohli V, Bharmal RN, Kartikeyan S et al. Cardiac troponins I and T: molecular markers for early diagnosis, prognosis, and accurate triaging of patients with acute myocardial infarction. Mol Diagn Ther. 2012;16(6):371-81. doi:10.1007/s40291-0120011-6.

5. Segraves JM, Frishman WH. Highly Sensitive Cardiac Troponin Assays: A Comprehensive Review of Their Clinical Utility. Cardiol Rev. 2015;23(6):282-9.

doi:10.1097/CRD.0000000000000087.

6. Di Angelantonio E, Chowdhury R, Sarwar N, Ray KK, Gobin R, Saleheen D et al. B-type natriuretic peptides and cardiovascular risk: systematic review and meta-analysis of 40 prospective studies. Circulation. 2009;120(22):2177-87.

doi:10.1161/CIRCULATIONAHA.109.884866. 
7. Buckley DI, Fu R, Freeman M, Rogers K, Helfand M. C-reactive protein as a risk factor for coronary heart disease: a systematic review and meta-analyses for the U.S. Preventive Services Task Force. Ann Intern Med. 2009;151(7):483-95.

8. Walldius G, Jungner I. Apolipoprotein A-I versus HDL cholesterol in the prediction of risk for myocardial infarction and stroke. Curr Opin Cardiol. 2007;22(4):359-67.

9. Greenland P, Alpert JS, Beller GA, Benjamin EJ, Budoff MJ, Fayad ZA et al. 2010 ACCF/AHA guideline for assessment of cardiovascular risk in asymptomatic adults: a report of the American College of Cardiology Foundation/American Heart Association Task Force on Practice Guidelines. Circulation. 2010;122(25):e584-636.

doi:10.1161/CIR.0b013e3182051b4c.

10. Melander O, Newton-Cheh C, Almgren P, Hedblad B, Berglund G, Engstrom G et al. Novel and conventional biomarkers for prediction of incident cardiovascular events in the community. JAMA. 2009;302(1):49-57. doi:10.1001/jama.2009.943.

11. Shah T, Casas JP, Cooper JA, Tzoulaki I, Sofat R, McCormack V et al. Critical appraisal of CRP measurement for the prediction of coronary heart disease events: new data and systematic review of 31 prospective cohorts. Int J Epidemiol. 2009;38(1):217-31. doi:10.1093/ije/dyn217.

12. de Lemos JA, Drazner MH, Omland T, Ayers CR, Khera A, Rohatgi A et al. Association of troponin T detected with a highly sensitive assay and cardiac structure and mortality risk in the general population. JAMA. 2010;304(22):2503-12. doi:10.1001/jama.2010.1768. 13. Schmidt C, Bergstrom G. Apolipoprotein B and apolipopotein A-I in vascular risk prediction - a review. Curr Pharm Des. 2014;20(40):6289-98.

14. Daniels LB, Clopton P, Laughlin GA, Maisel AS, Barrett-Connor E. Growthdifferentiation factor-15 is a robust, independent predictor of 11-year mortality risk in 
community-dwelling older adults: the Rancho Bernardo Study. Circulation.

2011;123(19):2101-10. doi:10.1161/CIRCULATIONAHA.110.979740.

15. Elliott P, Chambers JC, Zhang W, Clarke R, Hopewell JC, Peden JF et al. Genetic Loci associated with C-reactive protein levels and risk of coronary heart disease. JAMA. 2009;302(1):37-48. doi:10.1001/jama.2009.954.

16. Wang TJ, Gona P, Larson MG, Tofler GH, Levy D, Newton-Cheh C et al. Multiple biomarkers for the prediction of first major cardiovascular events and death. N Engl J Med. 2006;355(25):2631-9. doi:10.1056/NEJMoa055373.

17. Zethelius B, Berglund L, Sundstrom J, Ingelsson E, Basu S, Larsson A et al. Use of multiple biomarkers to improve the prediction of death from cardiovascular causes. $\mathrm{N}$ Engl $\mathrm{J}$ Med. 2008;358(20):2107-16. doi:10.1056/NEJMoa0707064.

18. Kim HC, Greenland P, Rossouw JE, Manson JE, Cochrane BB, Lasser NL et al. Multimarker prediction of coronary heart disease risk: the Women's Health Initiative. J Am Coll Cardiol. 2010;55(19):2080-91. doi:10.1016/j.jacc.2009.12.047.

19. Blankenberg S, Zeller T, Saarela O, Havulinna AS, Kee F, Tunstall-Pedoe H et al. Contribution of 30 biomarkers to 10 -year cardiovascular risk estimation in 2 population cohorts: the MONICA, risk, genetics, archiving, and monograph (MORGAM) biomarker project. Circulation. 2010;121(22):2388-97. doi:10.1161/CIRCULATIONAHA.109.901413. 20. Robinson DJ, Christenson RH. Creatine kinase and its CK-MB isoenzyme: the conventional marker for the diagnosis of acute myocardial infarction. J Emerg Med. 1999;17(1):95-104.

21. Zimmermann-Ivol CG, Burkhard PR, Le Floch-Rohr J, Allard L, Hochstrasser DF, Sanchez JC. Fatty acid binding protein as a serum marker for the early diagnosis of stroke: a pilot study. Mol Cell Proteomics. 2004;3(1):66-72. doi:10.1074/mcp.M300066-MCP200. 
22. Kleine AH, Glatz JF, Van Nieuwenhoven FA, Van der Vusse GJ. Release of heart fatty acid-binding protein into plasma after acute myocardial infarction in man. Mol Cell Biochem. 1992;116(1-2):155-62.

23. Donahue MP, Rose K, Hochstrasser D, Vonderscher J, Grass P, Chibout SD et al. Discovery of proteins related to coronary artery disease using industrial-scale proteomics analysis of pooled plasma. Am Heart J. 2006;152(3):478-85. doi:10.1016/j.ahj.2006.03.007. 24. Yin X, Subramanian S, Hwang SJ, O'Donnell CJ, Fox CS, Courchesne P et al. Protein biomarkers of new-onset cardiovascular disease: prospective study from the systems approach to biomarker research in cardiovascular disease initiative. Arterioscler Thromb Vasc Biol. 2014;34(4):939-45. doi:10.1161/ATVBAHA.113.302918.

25. Rezeli M, Vegvari A, Donnarumma F, Gidlof O, Smith JG, Erlinge D et al. Development of an MRM assay panel with application to biobank samples from patients with myocardial infarction. J Proteomics. 2013;87:16-25. doi:10.1016/j.jprot.2013.05.016.

26. Tang WH, Wu Y, Nicholls SJ, Hazen SL. Plasma myeloperoxidase predicts incident cardiovascular risks in stable patients undergoing medical management for coronary artery disease. Clin Chem. 2011;57(1):33-9. doi:10.1373/clinchem.2010.152827.

27. Kuster DW, Cardenas-Ospina A, Miller L, Liebetrau C, Troidl C, Nef HM et al. Release kinetics of circulating cardiac myosin binding protein-C following cardiac injury. Am J Physiol Heart Circ Physiol. 2014;306(4):H547-56. doi:10.1152/ajpheart.00846.2013. 28. Cubedo J, Padro T, Cinca J, Mata P, Alonso R, Badimon L. Retinol-binding protein 4 levels and susceptibility to ischaemic events in men. Eur J Clin Invest. 2014;44(3):266-75. doi:10.1111/eci.12229.

29. Lambadiari V, Kadoglou NP, Stasinos V, Maratou E, Antoniadis A, Kolokathis F et al. Serum levels of retinol-binding protein-4 are associated with the presence and severity of coronary artery disease. Cardiovasc Diabetol. 2014;13:121. doi:10.1186/s12933-014-0121-z. 
30. Martin-Ventura JL, Duran MC, Blanco-Colio LM, Meilhac O, Leclercq A, Michel JB et al. Identification by a differential proteomic approach of heat shock protein 27 as a potential marker of atherosclerosis. Circulation. 2004;110(15):2216-9.

doi:10.1161/01.CIR.0000136814.87170.B1.

31. Seibert TA, Hibbert B, Chen YX, Rayner K, Simard T, Hu T et al. Serum heat shock protein 27 levels represent a potential therapeutic target for atherosclerosis: observations from a human cohort and treatment of female mice. J Am Coll Cardiol. 2013;62(16):1446-54. doi:10.1016/j.jacc.2013.05.041.

32. Kardys I, Rifai N, Meilhac O, Michel JB, Martin-Ventura JL, Buring JE et al. Plasma concentration of heat shock protein 27 and risk of cardiovascular disease: a prospective, nested case-control study. Clin Chem. 2008;54(1):139-46. doi:10.1373/clinchem.2007.094961. 33. Jelic-Ivanovic Z, Bujisic N, Spasic S, Bogavac-Stanojevic N, Spasojevic-Kalimanovska V, Kotur-Stevuljevic J. Circulating sTWEAK improves the prediction of coronary artery disease. Clin Biochem. 2009;42(13-14):1381-6. doi:10.1016/j.clinbiochem.2009.06.001.

34. Martin-Ventura JL, Lindholt JS, Moreno JA, Vega de Ceniga M, Meilhac O, Michel JB et al. Soluble TWEAK plasma levels predict expansion of human abdominal aortic aneurysms. Atherosclerosis. 2011;214(2):486-9. doi:10.1016/j.atherosclerosis.2010.11.009.

35. Chorianopoulos E, Rosenberg M, Zugck C, Wolf J, Katus HA, Frey N. Decreased soluble TWEAK levels predict an adverse prognosis in patients with chronic stable heart failure. Eur J Heart Fail. 2009;11(11):1050-6. doi:10.1093/eurjhf/hfp139.

36. Turkmen K, Tonbul HZ, Erdur FM, Toker A, Biyik Z, Ozbiner H et al. Soluble TWEAK independently predicts atherosclerosis in renal transplant patients. BMC Nephrol.

2013;14:144. doi:10.1186/1471-2369-14-144. 
37. Zimmerli LU, Schiffer E, Zurbig P, Good DM, Kellmann M, Mouls L et al. Urinary proteomic biomarkers in coronary artery disease. Mol Cell Proteomics. 2008;7(2):290-8. doi:10.1074/mcp.M700394-MCP200.

38. Jensen MK, Rimm EB, Furtado JD, Sacks FM. Apolipoprotein C-III as a Potential Modulator of the Association Between HDL-Cholesterol and Incident Coronary Heart Disease. J Am Heart Assoc. 2012;1(2).

39. Mendivil CO, Rimm EB, Furtado J, Chiuve SE, Sacks FM. Low-density lipoproteins containing apolipoprotein C-III and the risk of coronary heart disease. Circulation. 2011;124(19):2065-72. doi:10.1161/CIRCULATIONAHA.111.056986.

40. Vaisar T, Pennathur S, Green PS, Gharib SA, Hoofnagle AN, Cheung MC et al. Shotgun proteomics implicates protease inhibition and complement activation in the antiinflammatory properties of HDL. J Clin Invest. 2007;117(3):746-56.

41. Alwaili K, Bailey D, Awan Z, Bailey SD, Ruel I, Hafiane A et al. The HDL proteome in acute coronary syndromes shifts to an inflammatory profile. Biochim Biophys Acta.

2012;1821(3):405-15. doi:S1388-1981(11)00138-7 [pii]

10.1016/j.bbalip.2011.07.013.

42. Chugh S, Ouzounian M, Lu Z, Mohamed S, Li W, Bousette N et al. Pilot study identifying myosin heavy chain 7, desmin, insulin-like growth factor 7, and annexin A2 as circulating biomarkers of human heart failure. Proteomics. 2013;13(15):2324-34.

doi:10.1002/pmic.201200455.

43. Mebazaa A, Vanpoucke G, Thomas G, Verleysen K, Cohen-Solal A, Vanderheyden M et al. Unbiased plasma proteomics for novel diagnostic biomarkers in cardiovascular disease: identification of quiescin Q6 as a candidate biomarker of acutely decompensated heart failure. Eur Heart J. 2012;33(18):2317-24. doi:10.1093/eurheartj/ehs162. 
44. Zhang J, Guy MJ, Norman HS, Chen YC, Xu Q, Dong X et al. Top-down quantitative proteomics identified phosphorylation of cardiac troponin I as a candidate biomarker for chronic heart failure. J Proteome Res. 2011;10(9):4054-65. doi:10.1021/pr200258m. 45. Simm A. Protein glycation during aging and in cardiovascular disease. J Proteomics. 2013;92:248-59. doi:10.1016/j.jprot.2013.05.012.

46. Heinecke JW. The role of myeloperoxidase in HDL oxidation and atherogenesis. Curr Atheroscler Rep. 2007;9(4):249-51.

47. Banfi C, Brioschi M, Barcella S, Veglia F, Biglioli P, Tremoli E et al. Oxidized proteins in plasma of patients with heart failure: role in endothelial damage. Eur J Heart Fail. 2008;10(3):244-51. doi:10.1016/j.ejheart.2008.01.016.

48. Napoli C, Zullo A, Picascia A, Infante T, Mancini FP. Recent advances in proteomic technologies applied to cardiovascular disease. J Cell Biochem. 2013;114(1):7-20. doi:10.1002/jcb.24307.

49. Shen X, Young R, Canty JM, Qu J. Quantitative proteomics in cardiovascular research: global and targeted strategies. Proteomics Clin Appl. 2014;8(7-8):488-505. doi:10.1002/prca.201400014.

50. Lindsey ML, Mayr M, Gomes AV, Delles C, Arrell DK, Murphy AM et al. Transformative Impact of Proteomics on Cardiovascular Health and Disease: A Scientific Statement From the American Heart Association. Circulation. 2015;132(9):852-72. doi:10.1161/cir.0000000000000226.

51. Menoret A, Crocker SJ, Rodriguez A, Rathinam VA, Clark RB, Vella AT. Transition from identity to bioactivity-guided proteomics for biomarker discovery with focus on the PF2D platform. Proteomics Clin Appl. 2015. doi:10.1002/prca.201500029.

52. Barderas MG, Vivanco F, Alvarez-Llamas G. Vascular proteomics. Methods Mol Biol. 2013;1000:1-20. doi:10.1007/978-1-62703-405-0_1. 


\section{ApoA-I}

CHFR-1

GST-omega-1

HSP27

RBP4

Secreted phosphoprotein 24

sTWEAK
Annexin A2

ApoC-I

ApoC-II

ApoE

BNP

CA11

Cardiac Tn I

CD59

CD5L

CK-MB

CMyBP-C

Collagen alpha-3(VI)

Collagen alpha-1(I)

Collagen alpha-1(III)

Collagen alpha-1(XVIII)

Complement $\mathrm{C} 1 \mathrm{~s}$

CRP
Cyclophilin A

Defensin 5

Desmin

Emilin 3/Multimerin-2

FABP

Fibrinogen $\gamma$ chain

GDF-15

IGF binding complex acid labile

chain

IGFBP7

MPO

MUC-18

Multimerin-2

MYH7

QSOX1

Salivary $\alpha$-amylase- 1

SCD40L 